\title{
A methodology to choose appropriate procurement standards in water and sewage projects
}

\author{
Pezhman Kouravand $^{\mathrm{a}^{*}}$, Nasim Shalamzari ${ }^{\mathrm{b}}$ and Zahra Ghalandari ${ }^{\mathrm{c}}$
}

${ }^{a}$ Rural Water \& Sewage Co., Ahvaz, Iran

${ }^{b}$ PhD Student in Environment Management, Kalijfar University of Applied Science and Technology, Sarbandar, Khouzestan, Iran

${ }^{c}$ Payam-e Noor University, Khouzestan Branch,, Ahvaz, Iran

\section{CHR ON I C L E A B S R A T}

Article history:

Received May 12, 2013

Received in revised format

12 September 2013

Accepted 6 October 2013

Available online

October 112013

Keywords:

Water and Sewage projects

Procurement standards

Supplier selection

Quality

\begin{abstract}
During the past few years, there have been increasing trend on building appropriate model for supplier selection and a good supplier, indeed, is capable of providing better quality products, which could lead to increase the productivity of an organization. In this paper, we present an empirical investigation to find the effect of monitoring three different standards, namely, domestic, national and international standard on improving the quality of products in water and sewage projects. The proposed model of this paper designs a questionnaire and distributes it among some experts in a rural Water \& Sewage firm located in city of Ahvaz, Iran. Using the Pearson correlation ratio, the study examines three hypotheses of the survey and the results indicate that there were poor relationship between carefully considering domestic, national and international standards and improvement on quality of products offered by various suppliers. In addition, job experience and type of employment also do not seem to have any meaningful effect on quality assessment of suppliers.
\end{abstract}

\section{Introduction}

Initial buying decisions such as make-or-buy decisions and supplier selection play essential role on the success of business units (De Boer et al., 2001). The nature of such decisions is normally complex and unstructured. In fact, planning sourcing strategies for various material groups provides a major challenge to most firms (Degraeve \& Roodhooft, 1998). There are literally various techniques, which could be used for this kind of decision making problems. Nevertheless, the application of outranking techniques in buying decisions has not been significantly recommended in purchasing or operations research literature. De Boer et al. (1998) demonstrated by means of a supplier selection example, that an outranking approach could be very well suited as a decision-making tool for initial purchasing decisions. Degraeve et al. (2000) presented a model to use the concept of "Total Cost of Ownership"

*Corresponding author. Tel: $+98-9166160572$

E-mail address: pkouravand@gmail.com (P. Kouravand) 
as a basis for comparing vendor selection models. They explained the comparison with a real life data set of the purchasing problem of ball bearings at Cockerill Sambre, a Belgian multinational firm in the steel industry. From a Total Cost of Ownership view point, their mathematical programming models outperformed rating models and multiple item models generating better results than single item models for this specific case study. Degraeve and Roodhooft (1998) proposed a mathematical programming technique based on activity based costing information to determine optimal order splitting among suppliers on the basis of the different costs associated with the buying decision.

Degraeve and Roodhooft (1999) presented a mathematical programming model that applies total cost of ownership information to simultaneously choose suppliers and to determine order quantities over a multi-period time horizon. The method was motivated by the purchasing problem of heating electrodes at Cockerill Sambre, a Belgian multinational steel producer where quality issues account for over $70 \%$ of the total cost of ownership making the quality of a supplier a critical success factor in the supplier selection process.

Many supplier selection problems are involved with more than one simple criterion, in other words, cost of goods and services does not have to be to account as primary source of decision making. Therefore, we need to consider various techniques and models for making appropriate purchasing decisions. Ghodsypour and O'brien (1998) are believed to be the first who presented an analytical hierarchy process (AHP) method for ranking various suppliers based on different criteria. They first used AHP to find the relative importance of various criteria and then they used a simple linear programming technique to decide the amount of goods ordered from each supplier. Kahraman et al. (2003) extended the supplier selection model by considering fuzzy AHP technique to handle uncertainty associated with input data. Wang et al. (2004) presented another technique for productdriven supply chain selection using integrated multi-criteria decision-making methodology. Cebi and Bayraktar (2003) presented a model for supplier selection problem structured as an integrated lexicographic goal programming (LGP) and AHP model including both quantitative and qualitative conflicting factors. The application process has been investigated in a food unit established in Istanbul, Turkey and the model building, solution and application processes of the proposed integrated model for supplier selection were discussed in details.

\section{The proposed model}

We present an empirical investigation to find the effect of monitoring three different standards, namely, domestic, national and international standard on improving the quality of products in water and sewage projects. The proposed model of this paper designs a questionnaire and distributes it among some experts in a Water \& Sewage firm located in city of Ahvaz, Iran. There are three hypotheses associated with the proposed study of this paper as follows,

1. There is a meaningful relationship between carefully following domestic standards and improvement on the quality of products offered by suppliers.

2. There is a meaningful relationship between carefully following national standards and improvement on the quality of products offered by suppliers.

3. There is a meaningful relationship between carefully following international standards and improvement on the quality of products offered by suppliers.

There are different standards around the world for measuring the quality of products and services such as Institute of Standards and Industrial Research of Iran (ISIRI), Deutsches Institut fur Normung din standards (DIN), British standard (BS), Japanese industrial standard (JIS) and American standard for testing \& material (ASTM). The proposed study of this paper considers all these standards in terms of three categories of domestic, national and international. Fig. 1 shows details of our proposed model. 


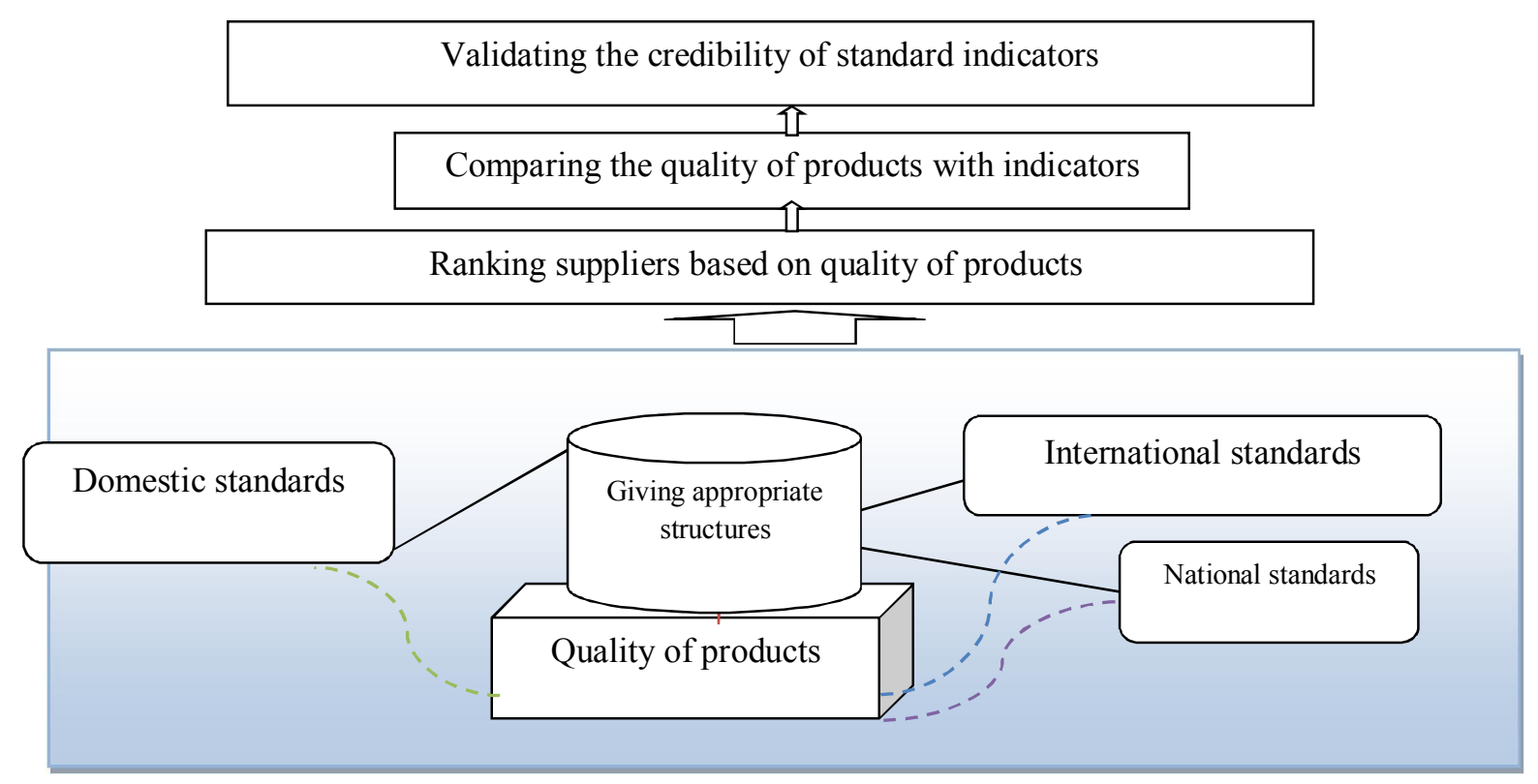

Fig. 1. The proposed model

The study uses three different scores for each standard and 200 experts express their insight about the effects of standard in three different categories summarized in Table 1 as follows,

Table 1

The summary of scores

\begin{tabular}{lcccccccccc}
\hline & Standard & \multicolumn{3}{c}{ National points } & \multicolumn{1}{c}{ International points } & \multicolumn{3}{c}{ Domestic points } \\
& & 1 & 2 & 3 & 1 & 2 & 3 & 1 & 2 & 3 \\
\hline 1 & Quality & 40 & 30 & 30 & 30 & 40 & 30 & 30 & 30 & 30 \\
2 & Production & 30 & 25 & 20 & 25 & 30 & 20 & 20 & 25 & 40 \\
3 & Installation & 30 & 25 & 20 & 25 & 30 & 20 & 20 & 25 & 30 \\
\hline \multicolumn{2}{l}{ Emphasize } & 100 & 80 & 70 & 80 & 100 & 70 & 70 & 80 & 100 \\
\hline
\end{tabular}

\section{The results}

In this section, we present details of our findings on testing various hypotheses of the survey.

\subsection{The first hypothesis: The relationship between considering domestic standards and quality}

The first hypothesis of this survey investigates whether applying domestic standards improves the quality of goods and services provided by different suppliers, which are active in in water and sewage projects or not. The results of applying Pearson correlation yields $\mathrm{r}=0.125$ with $\mathrm{Sig}=0.077$, which means there is a weak relationship between domestic standards and quality and the null hypothesis can be reject only when the level of significance is ten percent.

\subsection{The second hypothesis: The relationship between considering national standards and quality}

The second hypothesis of this survey tries to find out whether applying national standards improves the quality of goods and services provided by various suppliers, which are active in in water and sewage projects or not. The results of applying Pearson correlation yields $r=0.094$ with Sig $=0.091$, which means there is a very weak relationship between domestic standards and quality and the null hypothesis can be reject only when the level of significance is ten percent. 
The third hypothesis of this survey tries to find out whether applying international standards improves the quality of goods and services provided by various suppliers, which are active in in water and sewage projects or not. The results of applying Pearson correlation yields $\mathrm{r}=0.071$ with $\mathrm{Sig}=0.083$, which means there is a very weak relationship between international standards and quality and the null hypothesis can be reject only when the level of significance is ten percent.

In addition, job experience and type of employment also do not seem to have any meaningful effect on quality assessment of suppliers.

\section{Conclusion}

In this paper, we have presented an empirical investigation to find the relationship between considering different types of standards and quality improvement among various suppliers, which are active in water and sewage projects. There seems to be a weak relationship between these items but an implementation of AHP method indicates that international standards have better capabilities than national and domestic standards. We recommend using the scores given in Table 2 for assessing suppliers.

\section{Table 2}

The suggested scores

\begin{tabular}{lccc}
\hline Standard & National & International & Domestic \\
\hline Quality & 30 & 40 & 30 \\
Production & 25 & 30 & 20 \\
Installation & 25 & 30 & 20 \\
\hline
\end{tabular}

\section{References}

Cebi, F., \& Bayraktar, D. (2003). An integrated approach for supplier selection. Logistics Information Management, 16(6), 395-400.

De Boer, L., van der Wegen, L., \& Telgen, J. (1998). Outranking methods in support of supplier selection. European Journal of Purchasing \& Supply Management, 4(2), 109-118.

De Boer, L., Labro, E., \& Morlacchi, P. (2001). A review of methods supporting supplier selection. European Journal of Purchasing \& Supply Management,7(2), 75-89.

Degraeve, Z., Labro, E., \& Roodhooft, F. (2000). An evaluation of vendor selection models from a total cost of ownership perspective. European Journal of Operational Research, 125(1), 34-58.

Degraeve, Z., \& Roodhooft, F. (1998). Determining sourcing strategies: a decision model based on activity and cost driver information. Journal of the Operational Research Society, 781-789.

Degraeve, Z., \& Roodhooft, F. (1999). Improving the efficiency of the purchasing process using total cost of ownership information: The case of heating electrodes at Cockerill Sambre SA. European Journal of Operational Research, 112(1), 42-53.

Ghodsypour, S. H., \& O'brien, C. (1998). A decision support system for supplier selection using an integrated analytic hierarchy process and linear programming. International journal of production economics, 56, 199-212.

Kahraman, C., Cebeci, U., \& Ulukan, Z. (2003). Multi-criteria supplier selection using fuzzy AHP. Logistics Information Management, 16(6), 382-394.

Wang, G., Huang, S. H., \& Dismukes, J. P. (2004). Product-driven supply chain selection using integrated multi-criteria decision-making methodology. International journal of production economics, 91(1), 1-15. 